\title{
Honey-Based Salve and Burdock Leaf Dressings as an Alternative to Surgical Debridement of a Traumatic Wound Eschar
}

\author{
Adam Schell, Jonathan Copp, ${ }^{1}$ Kath M. Bogie, ${ }^{1,2, *}$ and Robert Wetzel ${ }^{1}$ \\ ${ }^{1}$ Department of Orthopaedics, Case Western Reserve University, Cleveland, Ohio. \\ ${ }^{2}$ APT Center of Excellence, Louis Stokes Cleveland VA Medical Center, Cleveland, Ohio.
}

Objective: Nonviable necrotic eschar is an impedance to wound healing and can ultimately lead to failure of soft tissue coverage in traumatic or high-risk wounds. Topical therapeutic agents can provide a less invasive management alternative to surgical debridement of eschar.

Approach: The case of a 40-year-old male with a traumatic right lower extremity amputation complicated by surgical incision ischemic eschar formation is reported. Honey-based salve with burdock leaf dressings was used to noninvasively manage eschar extending over the incision site. Images were obtained for 5 months of follow-up.

Results: Five-month follow-up demonstrated complete resolution of eschar and re-epithelialization of skin in the affected region.

Innovation: Honey-based salve with burdock leaf dressings shows promise for enhancing healing outcomes in traumatic wounds that develop nonviable eschar. Conclusion: Surgical debridement of an amputation stump with large ischemic eschar was avoided with the use of honey-based salve with burdock leaf dressings.

Keywords: eschar treatment, biological therapeutic dressing, traumatic amputation

\section{INTRODUCTION}

THE SEVERELY MANGLED extremity is a challenging clinical problem for the treating surgeon that predisposes trauma survivors to substantial morbidity and loss of function. ${ }^{1-3}$ In the acute setting, patients often present with active hemorrhage through the mangled extremity and orthopedic injuries too severe for successful limb salvage to occur. When hemorrhage through a mangled extremity cannot be controlled, amputation is some- times performed, with careful consideration for maintaining as much native limb as possible when appropriate. Amputation in these cases allows hemostasis to occur. Attention can then be focused on resuscitating the patient and treating any other associated but less severe injuries.

After amputation is performed, a series of challenges must be overcome. Open fractures and contamination of the initial injury predispose the patient to infection. ${ }^{4}$ In addition,

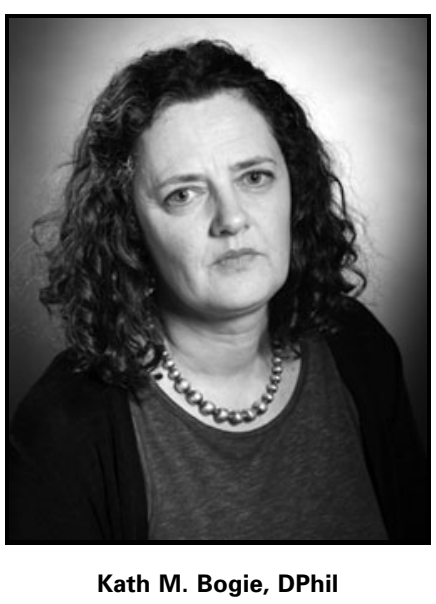

Submitted for publication June 27, 2018. Accepted in revised form September 17, 2018. *Correspondence: Department of Orthopaedics, Case Western Reserve University, Cleveland, $\mathrm{OH}$ 44106, (e-mail: kmb3@case.edu).

(C) Adam Schell et al., 2018; Published by Mary Ann Liebert, Inc. This Open Access article is distributed under the terms of the Creative Commons Attribution Noncommercial License (http://creativecommons .org/licenses/by-nc/4.0/), which permits any noncommercial use, distribution, and reproduction in any medium, provided the original authors and the source are cited. 
the full extent of soft tissue injury is often difficult to ascertain in the immediate postoperative period after amputation. Barriers to successful healing of traumatic and surgical wounds in the setting of amputation are often encountered in the following days and weeks as the zone of injury declares itself, presenting as inadequate soft tissue flap perfusion, poor host nutrition, and soft tissue infection. ${ }^{5}$

When wound healing complications are encountered, the options available to the surgeon to improve the clinical outcome may be limited based on patient preference or the wound characteristics themselves. ${ }^{6}$ Surgical debridement and wound bed preparation followed by split thickness skin grafting or even more advanced flaps and grafts have been suggested to be the standard of care for definitive closure of acute and chronic wounds not amendable to primary closure. However, patients wish to avoid multiple trips to the operating theater and alternative wound management strategies should be considered. ${ }^{7-9}$ In these scenarios, effective nonsurgical strategies for mitigating traumatic wound complications are of keen interest to surgeons and their patients. Negative pressure wound therapy (NPWT), hyperbaric oxygen, and enzymatic debridement are commonly used nonsurgical alternatives. ${ }^{10-12}$ Wet to dry dressings with antiseptic solutions such as Dakins or betadine are also used, ${ }^{13}$ although there is growing concern that they do not provide an appropriate moist wound healing environment. ${ }^{14}$

Both patients and surgeons may be interested in the alleviation of traumatic wound complications without recourse to further surgery. Reports of topical biological therapeutic agents have shown promise. Honey-based salves that have been utilized as a wound dressing for centuries have more recently been found to have demonstrable antioxidant, antimicrobial, anti-inflammatory, and angiogenic properties. ${ }^{15}$ Furthermore, honey has been shown to debride wound slough mechanically, penetrate biofilm, reduce wound $\mathrm{pH}(3.5-4)$, increase local oxygen release from hemoglobin, and even promote fibroblast infiltrate. ${ }^{16,17}$ Honey has been shown to promote tissue healing in a variety of settings, most notably burn wounds and dehisced surgical wound beds. ${ }^{18}$

All parts of the burdock plant (Acrtium lappa) are used in traditional medicine. The leaves in particular are thought to have antibacterial and antifungal properties. ${ }^{19}$ The Amish community has used a natural dressing comprising honey-based B\&W Ointment ${ }^{\mathrm{TM}}$ (Holistic Acres, LLC, Newcomerstown, $\mathrm{OH}$ ) and burdock leaves to treat burns and wounds. ${ }^{20}$ It has previously been reported as being a successful alternative treatment for traumatic wounds requiring skin grafts, particularly in children. ${ }^{21}$ The Amish Burn Group reported that B\&W ointment and burdock leaf therapy almost totally alleviated the distress caused by changing burn wound dressings and appeared to be an acceptable alternative to conventional burn care. ${ }^{22}$ However, others found limited efficacy on in vivo testing and recommended caution in the use of this complementary topical therapeutic for burn wounds. ${ }^{23}$ A literature search on the use of honey-based $\mathrm{B} \& \mathrm{~W}$ ointment and burdock leaves for complications of complex traumatic wounds other than burns revealed no prior reports. The current article presents a case report on the effective use of this honey-based biological therapeutic intervention on a complex traumatic crush wound with complications, specifically tissue necrosis and eschar development.

\section{CLINICAL PROBLEM ADDRESSED}

Nonviable necrotic eschar is an impedance to wound healing and can ultimately lead to failure of soft tissue coverage of a lower extremity amputation stump. When present, this eschar can create a mechanical blockade to wound epithelialization, prolong the inflammatory component of the woundhealing mechanism, and serve as a nidus for soft tissue infection. For these reasons, surgeons classically opt for sharp debridement of eschar and revision of a wound closure to include skin grafts or vascularized flaps. Efforts to identify less invasive strategies for managing this complication have yielded a number of alternative debridement techniques. In this report, we present a case study wherein honey was utilized in combination with burdock leaves to promote successful healing of a traumatic transfemoral amputation surgical wound complicated by tissue necrosis without the need for further surgical revision in a patient opposed to additional surgery.

\section{MATERIALS AND METHODS}

A 40-year-old Amish male laborer's right leg was caught beneath a loaded wooden shipping pallet weighing $>275 \mathrm{~kg}$, which had fallen from a height during a freight lift accident at his workplace. He sustained a traumatic amputation of his right leg at the level of the proximal tibia and an ipsilateral closed femoral shaft fracture (Fig. 1A, B). He presented to our level 1 trauma facility in extremis, actively exsanguinating from the injured limb. His leg was found to be pulseless below the level of his 

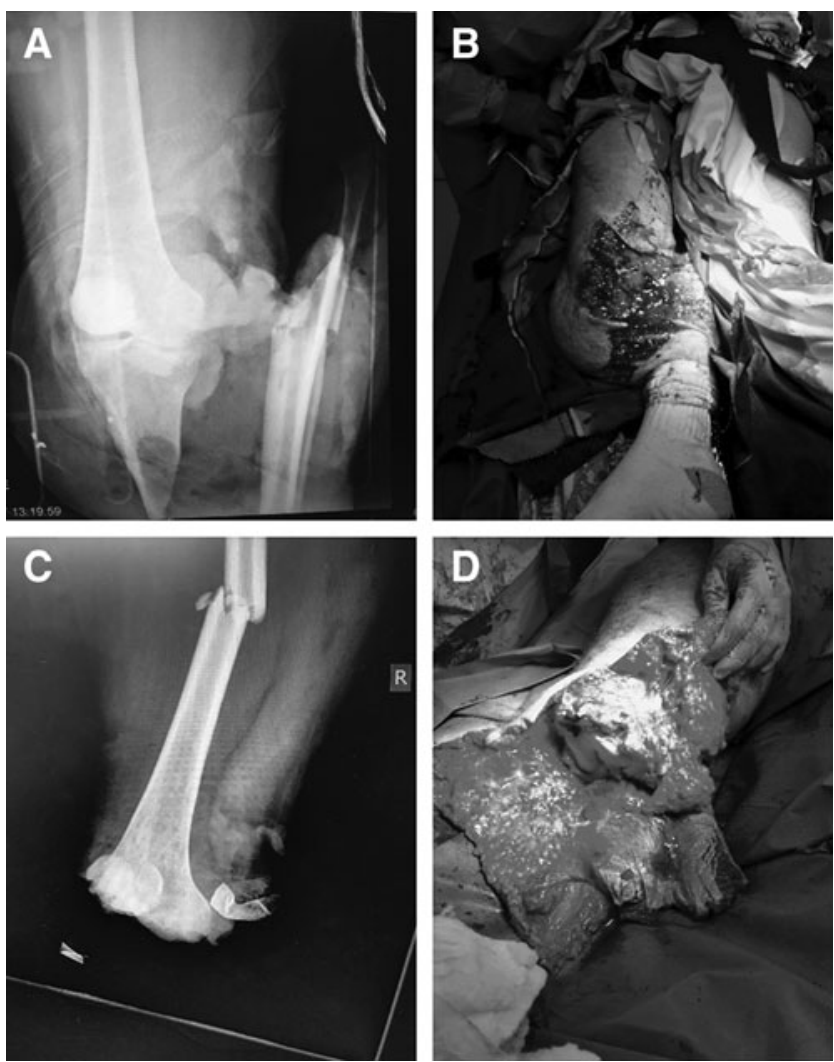

Figure 1. Initial presentation of traumatic amputation. Injury X-ray (A) and clinical photo (B) demonstrating traumatic amputation. Postinitial debridement X-ray (C) with ipsilateral femur fracture and clinical photo (D) of remaining viable tissue.

injuries, and he was unable to demonstrate distal neurologic function. He was taken emergently to the operating room for knee disarticulation and hemostasis of a popliteal arterial avulsion injury (Fig. 1C, D). After disarticulation had been performed and hemostasis was achieved, he underwent resuscitation using the massive transfusion protocol. The surgical wound was packed with sterile laps and an NPWT dressing was utilized to bolster the initial wound (Fig. 2A-D). In addition, he was placed in a long leg splint to initially immobilize his femoral shaft injury and enable soft tissue rest to minimize any further microtrauma to an already threatened extremity.

The following day he underwent revision amputation for definitive treatment of his extremity injury. The amputation was revised to above the knee using a Gritti-Stokes technique, with ipsilateral intramedullary fixation of the femoral shaft fracture using a retrograde femoral nail (Fig. 3A, B). The Gritti-Stokes method maintains the patella and quadriceps tendon by performing a patellofemoral arthrodesis. This allows for improvement in hip flexor strength and mobility of
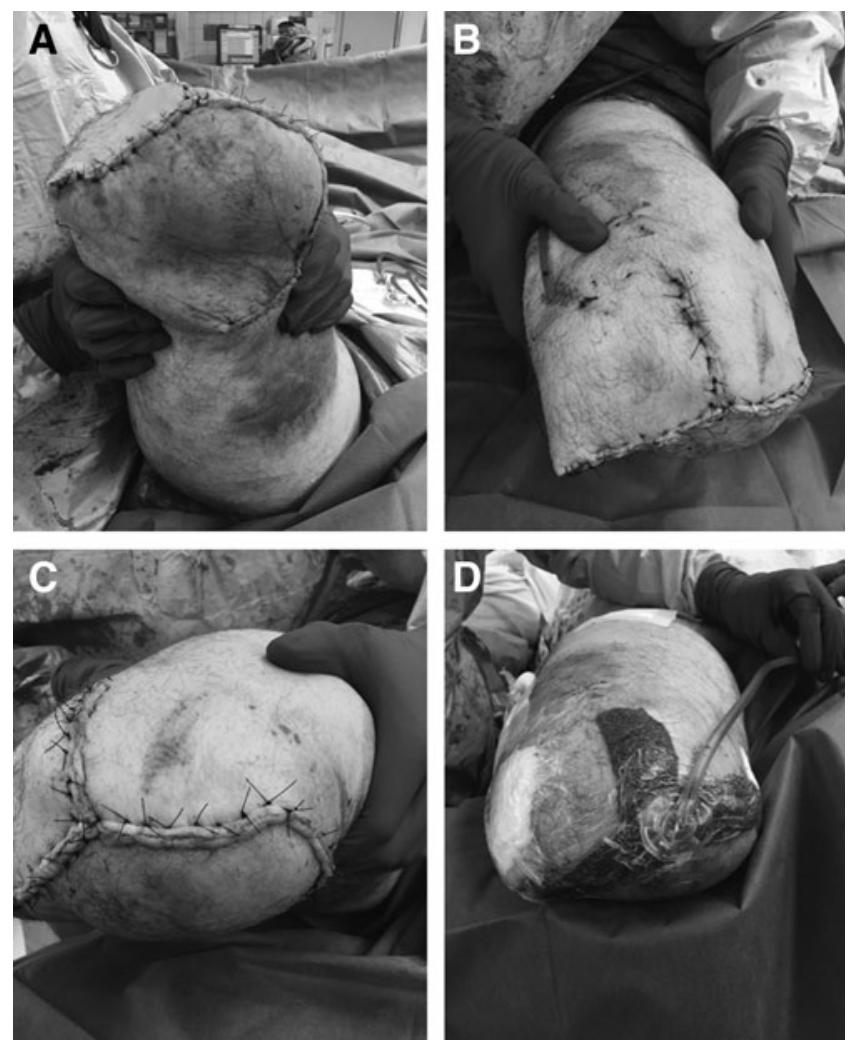

Figure 2. Clinical presentation after initial debridement of posterior flap. (A) Anterior repair and drain (B) and distal medial repair (C) with application of NPWT (D). NPWT, negative pressure wound therapy.

the amputation stump. ${ }^{24}$ Coverage of the distal femur was achieved using two anterior-based fasciocutaneous flaps of tissue from his thigh and a posterolateral-based fasciocutaneous flap advanced to the medial wound edge under tensionless closure. Intraoperatively, both anterior flaps appeared viable with bleeding wound edges, indicative of good perfusion. The posterior flap was the most traumatized and appeared to have questionable viability with less consistent perfusion to the edges; however, due to the fact that his posterior thigh would require very large graft if resected, it was utilized as a biological dressing in the acute setting to allow for formal zone of injury declaration. The incision was bolstered by reapplication of NPWT (Fig. 3C, D). The NPWT dressing was continued for 2 weeks postoperatively, and stump shrinker stockings were initiated on postoperative day 3 to maintain external support of the wound in lieu of a bulkier splint dressing but also to allow wound checks while in the hospital.

The patient remained in the hospital and was maintained supine for 5 days postoperatively before discharge home. He was then followed with regular clinic visits at $1,3,5,7,10$, and 14 weeks by 

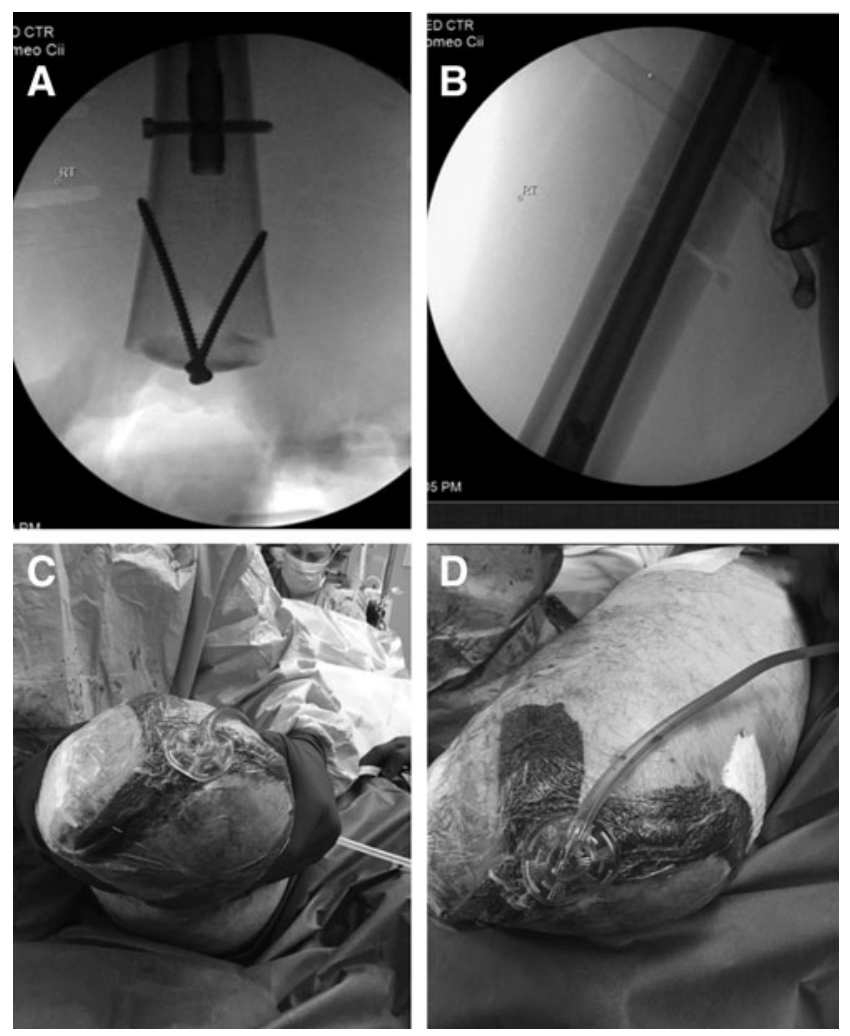

Figure 3. Clinical status after Gritti-Stokes amputation. Arthrodesis of patella to the femoral stump (A) fracture reduction (B) and three-limbed flap (C) with application of NPWT (D).

the treating surgeon. At his first postoperative evaluation, there was a large area $(\sim 30 \times 12 \mathrm{~cm})$ of skin pallor and tissue necrosis noted on the posterior medial soft tissue flap (Fig. 4A, B), which had been in the initial zone of injury and used for a local fasciocutaneous flap. This portion of the wound appeared nonviable and had started to form a thick eschar beginning at the surgical wound edge and progressing proximally up the posterior medial thigh. At this time, surgical debridement of the eschar and coverage of the amputation stump with split-thickness skin grafting were offered; however, the patient declined. He requested a trial of local wound care with burdock leaf dressing wraps and a honey-based salve, which was a wound care strategy that has worked for others in his community. His wound did not appear infected, specifically there was no marginal erythema, purulence, or local odor, and there were no systemic symptoms of infection. His request was, therefore, honored, and his wound was monitored closely over the subsequent weeks. He utilized a thin layer of B\&W ointment applied to burdock leaves $\left(\sim 2^{\prime \prime} \times 4^{\prime \prime}\right)$ obtained from the local Amish community healthcare supply provider. The leaves were left to soften for
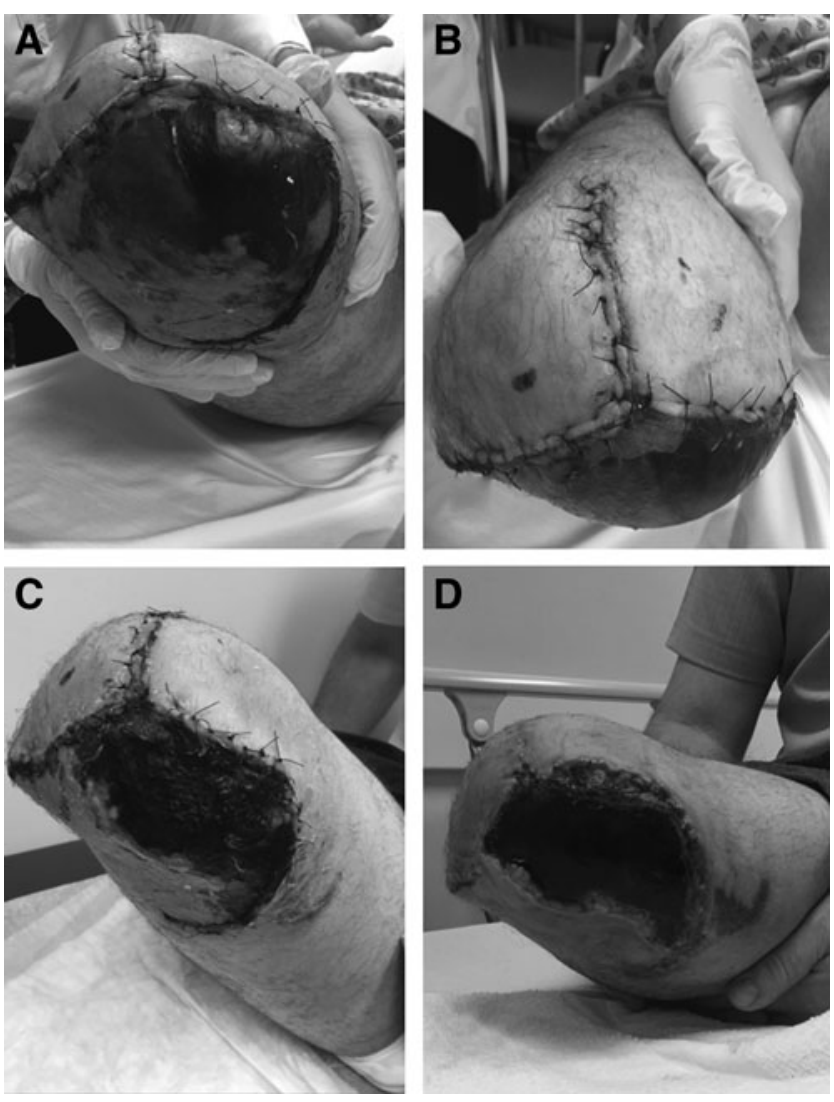

Figure 4. Postoperative evaluation. Development of large posteromedial eschar at 1 week (A) with preservation of two anterior flaps (B). Maturation of eschar at 3 weeks (C) and 5 weeks (D).

15 min before being individually applied to the eschar and his stump and wrapped in cotton gauze to secure them in place. The dressings were changed twice daily. At his 3-week postoperative follow-up, the eschar was evolving and was more firm with the periphery retracted, revealing a granulation bed without erythema, purulent, or malodorous discharge or any systemic symptom indicative of infection (Fig. 4C). Sutures were removed at 5 -week postoperative follow-up. At this point, the eschar showed continued evolution with additional contraction, revealing a larger granulation bed at the periphery of the wound (Fig. 4D).

\section{RESULTS}

This patient-selected conservative honey and burdock treatment strategy was highly effective for this individual both clinically and regarding his goal to avoid further surgical management if possible. The eschar had nearly completely lysed away by postoperative week 7 and was sharply excised through several intact fibrous adhesions to the underlying granulating bed as a single piece of 

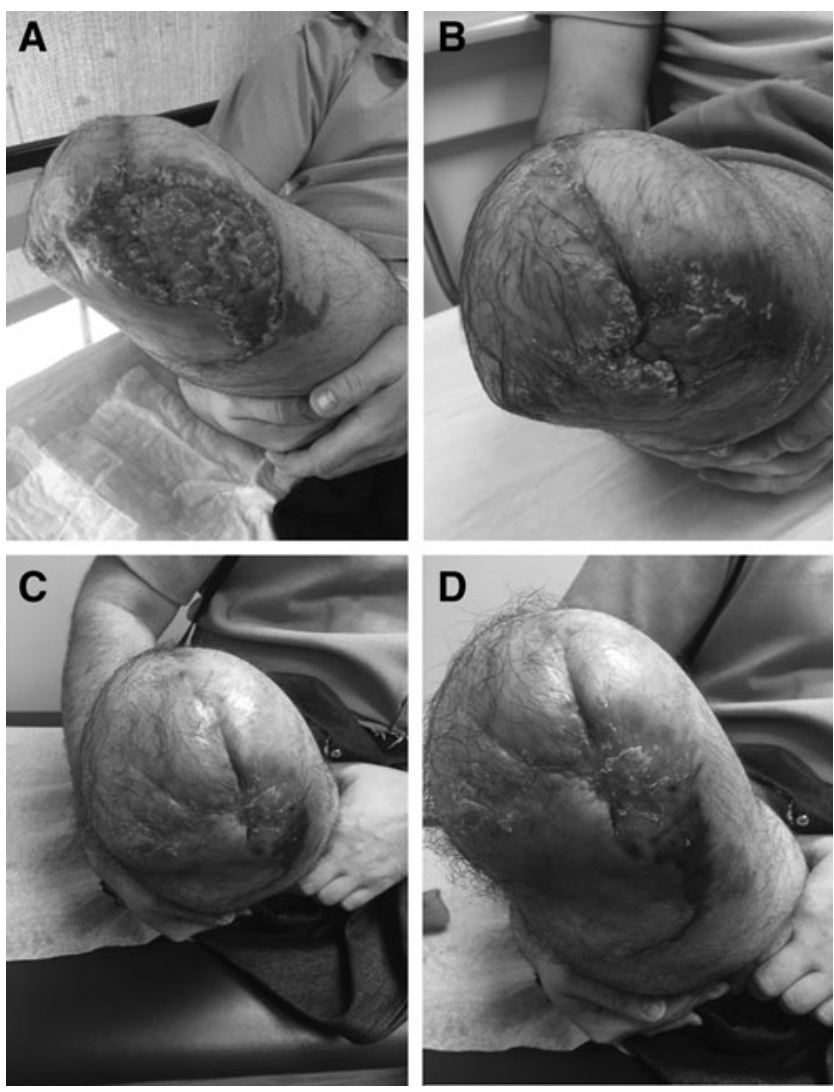

Figure 5. Post-therapeutic appearance. Progression of wound after eschar removal at 7 weeks (A) 10 weeks (B), and 14 weeks postoperative follow-up demonstrating intact distal medial and lateral coverage (C) and posteromedial coverage (D).

tissue (Fig. 5A). The honey and burdock treatment was continued by the patient after eschar debridement for a total of 14 weeks. Of note, the patient developed a transient folliculitis during this time period, which was suspected to be due to moisture accumulation and sweat. The patient was advised to minimize the cotton gauze wrapping to allow greater permeability and the rash spontaneously resolved without use of antibiotics within 3-4 days. By week 10, the underlying wound bed was re-epithelialized with primarily healthy tissue except for mild posteromedial erythema and presence of a benign exudative process, with minimal serous fluid, with several superficial erosions indicative of final stages of healing (Fig. 5B). These lesions were treated by superficial debridement in the clinic by the treating surgeon. At no point during follow-up was there concern for infection. By week 14, his stump had matured and was in acceptable form to bear weight through an abovethe-knee prosthetic device as evident by viable and healed anterior/distal flaps (Fig. 5C) and posterior soft tissue flaps (Fig. 5D).

\section{DISCUSSION}

The patient presented in this case study did not use tobacco and was generally healthy, with adequate nutritional status, no peripheral vascular disease. The patient was also highly motivated to adhere to the treatment. The patient was able to accommodate regular follow-up to assess wound status for possible complications, which would contraindicate a conservative course.

Moisture retentive dressing strategies are reported to promote wound eschar autolysis by leveraging the body's endogenous proteolytic, fibrinolytic, and collagenolytic mechanisms. ${ }^{25}$ Larval therapy, a different technique requiring application of sterile maggots to the wound eschar, has been shown to effectively debride and also promote tissue granulation. Larvae are particularly effective in the setting of infection, as they have been shown to eradicate bacterial biofilms during the debridement process. ${ }^{26}$ In scenarios wherein eschar is present but soft tissue infection is not suspected, application of topical solvents, such as Dakins solution, or exogenous enzymes such as collagenase, can assist in degradation of devitalized tissue. In this case report, we introduce honey and burdock leaves as another less invasive debridement strategy for addressing wound eschar that does not appear infected.

$\mathrm{B} \& \mathrm{~W}$ ointment is predominantly honey, a biologic agent that has been widely studied and used in wound therapy. ${ }^{27}$ There has been increased interest in the role of honey, not least because it may reduce the need for antibiotic therapies. Recent studies have also indicated that honey may have an active regenerative role. ${ }^{28}$ It is thought that honey acts to modulate the immune response by stimulation and/or inhibition of regulatory cytokines, such as tumor necrosis factor- $\alpha$, interleukin- $1 \beta$, and interleukin- $6{ }^{29}$ Other active constituents of $\mathrm{B} \& \mathrm{~W}$ ointment, such as aloe vera gel, ${ }^{30}$ comfrey root, ${ }^{31}$ and wormwood, ${ }^{32}$ have been investigated individually and shown to be effective in reducing bacterial and fungal activity.

The use of burdock leaves has been less studied in the wound care field. The literature on the medicinal use of burdock leaves focuses on burdock leaf extract rather than whole leaves. ${ }^{33}$ For example, in dentistry this biologic agent is thought to be effective against oral infections. Pereira et al. studied the antimicrobial activity of burdock leaf extract on several strains of bacteria that are also implicated in soft tissue wound infection, specifically Pseudomonas aeruginosa, Staphylococcus aureus, and Candida albicans. ${ }^{34}$ They found that the complex 
chemical profile of the burdock leaves enables antimicrobial action on several different microbial inhibition zones, indicating burdock leaves appear to have broad antimicrobial efficacy.

\section{Limitations}

If tissue is deemed completely nonviable in the initial evaluation of the injury, or infection threatens the soft tissue envelope, then sharp debridement and swift intervention are indicated. Allergies to honey or burdock leaves will contraindicate use of these biologics.

Honey-based salve with burdock leaf dressings was used in combination in this case of patient-centered care in managing the severely mangled extremity. Further study is needed to determine whether honey-based salve or burdock leaf dressings used alone would have similar efficacy in eschar management for this type of injury.

\section{INNOVATION}

Conservative management using a honey-based salve may be a reasonable alternative in the appropriate patient population with close follow-up, in lieu of repeat surgical debridement and placement of skin grafts. Biologic agents have the potential to enhance healing and reduce incident infection. Although the use of honey is commonly reported in diabetic wounds and burn wounds, this case report is, to our knowledge, the first description of honey-based salve and burdock leaves being utilized as a less-invasive alternative to sharp debridement and skin grafting of a traumatic wound eschar to achieve coverage. Necrotic eschar is an impedance to wound healing and can ultimately lead to failure of soft tissue coverage of a lower extremity amputation stump.

\section{ACKNOWLEDGMENTS AND FUNDING SOURCES}

The authors have no acknowledgements. The case study presented is an unfunded study.

\section{AUTHOR DISCLOSURES AND GHOSTWRITING}

No competing financial interests exist. The content of this article was expressly written by the authors listed. No ghostwriters were used to write this article.

\section{ABOUT THE AUTHORS}

Adam Schell, MD, is a third year orthopedic surgery resident at Case Western Reserve University Jonathan Copp, MD, is a third year orthopedic surgery resident at Case Western Reserve University Kath M. Bogie, DPhil, is a biomedical engineer whose research interests focus on translational research, particularly in the prevention and treatment of wounds, from biomolecular techniques to clinical assessment and medical device development. Dr. Bogie is an associate professor in the Department of Orthopaedics at Case Western Reserve University and a member of the Board of Directors for the Wound Healing Society. Robert Wetzel, MD, is an orthopedic trauma surgeon at University Hospitals Case Medical Center and Assistant Professor at Case Western Reserve University in the Department of Orthopaedics.

\section{REFERENCES}

1. Herard P, Boillot F. Amputation in emergency situations: indications, techniques and Médecins Sans Frontières France's experience in Haiti. Int Orthop 2012;36:1979-1981.

2. Schirò GR, Sessa S, Piccioli A, Maccauro G. Primary amputation vs limb salvage in mangled extremity: a systematic review of the current scoring system. BMC Musculoskelet Disord 2015;16:372.

3. Shawen SB, Keeling JJ, Branstetter J, Kirk KL, Ficke JR. The mangled foot and leg: salvage versus amputation. Foot Ankle Clin 2010;15:63-75
4. Nobert N, Moremi N, Seni J, et al. The effect of early versus delayed surgical debridement on the outcome of open long bone fractures at Bugando Medical Centre, Mwanza, Tanzania. J Trauma Manag Outcomes 2016;10:6.

5. Melcer T, Walker J, Bhatnagar V, Richard E, Sechriest VF 2nd, Galarneau M. A comparison of four-year health outcomes following combat amputation and limb salvage. PLoS One 2017;12:e0170569.

6. Weinstein JN, Clay K, Morgan TS. Informed patient choice: patient-centered valuing of surgical risks and benefits. Health Aff (Millwood) 2007:26: 726-730.

7. Gacto-Sanchez P. Surgical treatment and management of the severely burn patient: review and update. Med Intensiva 2017:41:356-364.

8. Hierner R, Degreef H, Vranckx JJ, Garmyn M Massagé $P$, van Brussel $M$. Skin grafting and wound healing-the "dermato-plastic team approach". Clin Dermatol 2005;23:343-352

9. Simman R, Phavixay L. Split-thickness skin grafts remain the gold standard for the closure of large 
acute and chronic wounds. J Am Col Certif Wound Spec 2011;3:55-59.

10. Iheozor-Ejiofor Z, Newton K, Dumville JC, Costa ML, Norman G, Bruce J. Negative pressure wound therapy for open traumatic wounds. Cochrane Database Syst Rev 2018;7:CD012522.

11. Eskes AM, Ubbink DT, Lubbers MJ, Lucas C, Vermeulen H. Hyperbaric oxygen therapy: solution for difficult to heal acute wounds? Systematic review. World J Surg 2011;35:535-542.

12. Dabiri G, Damstetter E, Phillips T. Choosing a wound dressing based on common wound characteristics. Adv Wound Care (New Rochelle) 2016; 5:32-41.

13. Levine JM. Dakin's solution: past, present, and future. Adv Skin Wound Care 2013;26:410414.

14. Dale BA, Wright DH. Say goodbye to wet-to-dry wound care dressings: changing the culture of wound care management within your agency. Home Healthc Nurse 2011;29:429-440.

15. Abd Jalil MA, Kasmuri AR, Hadi H. Stingless bee honey, the natural wound healer: a review. Skin Pharmacol Physiol 2017;30:66-75.

16. Minden-Birkenmaier BA, Bowlin GL. Honey-based templates in wound healing and tissue engineering. Bioengineering (Basel) 2018;5:pii:E46.

17. Lu J, Turnbull L, Burke CM, et al. Manuka-type honeys can eradicate biofilms produced by Staphylococcus aureus strains with different biofilmforming abilities. PeerJ 2014;2:e326.

18. Jull AB, Cullum N, Dumville JC, Westby MJ, Deshpande S, Walker N. Honey as a topical treatment for wounds. Cochrane Database Syst Rev 2015;6:CD005083.
19. Holetz FB, Pessini GL, Sanches NR, Cortez DA, Nakamura CV, Filho BP. Screening of some plants used in the Brazilian folk medicine for the treatment of infectious diseases. Mem Inst Oswaldo Cruz 2002;97:1027-1031.

20. Keim JW, ed. Burn aid written for the Amish by the Amish. Raleigh, NC: Barefoot Publicaitons, 2006.

21. Flurry MD, Herring KL, Carr LW, Hauck RM, Potochny JD. Salve and burdock: a safe, effective amish remedy for treatment of traumatic wounds? Adv Skin Wound Care 2017;30:213-217.

22. Amish Burn Study Group, Kolacz NM, Jaroch MT, Bear ML, Hess RF. The effect of Burns \& Wounds $(B \& W) /$ burdock leaf therapy on burn-injured Amish patients: a pilot study measuring pain levels, infection rates, and healing times. $J$ Holist Nurs 2014;32:327-340.

23. Rieman MT, Neely AN, Boyce ST, et al. Amish burn ointment and burdock leaf dressings: assessments of antimicrobial and cytotoxic activities. J Burn Care Res 2014;35:e217-e223.

24. Taylor BC, Poka A, French BG, Fowler TT, Mehta S. Gritti-stokes amputations in the trauma patient: clinical comparisons and subjective outcomes. $J$ Bone Joint Surg Am 2012;94:602-608.

25. Ramundo J. Wound debridement. In: Bryant RA, Nix DP, eds. Acute and Chronic Wounds. Current management concepts 4th ed. St. Louis, MO: Elsevier-Mosby, 2012:279-288.

26. Opletalová K, Blaizot X, Mourgeon B, et al. Maggot therapy for wound debridement: a randomized multicenter trial. Arch Dermatol 2012; 148:432-438.

27. Al-Waili N, Salom K, Al-Ghamdi AA. Honey for wound healing, ulcers, and burns; data supporting its use in clinical practice. Scientific World Journal 2011;11:766-787.

28. Martinotti S, Bucekova M, Majtan J, Ranzato E. Honey: an effective regenerative medicine product in wound management. Curr Med Chem 2018 [Epub ahead of print]; DOI: 10.2174/ 0929867325666180510141824.

29. Majtan J. Honey: an immunomodulator in wound healing. Wound Repair Regen 2014;22:187-192.

30. Fox LT, Mazumder A, Dwivedi A, Gerber M, du Plessis J, Hamman JH. In vitro wound healing and cytotoxic activity of the gel and whole-leaf materials from selected aloe species. J Ethnopharmacol 2017;200:1-7.

31. Sowa I, Paduch R, Strzemski M, et al. Proliferative and antioxidant activity of Symphytum officinale root extract. Nat Prod Res 2018;32:605-609.

32. Trinh $\mathrm{H}, \mathrm{Yoo}_{\mathrm{Y}} \mathrm{Y}$, Won $\mathrm{KH}$, et al. Evaluation of invitro antimicrobial activity of Artemisia apiacea $\mathrm{H}$. and Scutellaria baicalensis G. extracts. J Med Microbiol 2018;67:489-495.

33. Ferracane R, Graziani G, Gallo M, Fogliano V, Ritieni A. Metabolic profile of the bioactive compounds of burdock (Arctium lappa) seeds, roots and leaves. J Pharm Biomed Anal 2010;51:399-404.

34. Pereira JV, Bergamo DC, Pereira JO, França Sde C, Pietro RC, Silva-Sousa YT. Antimicrobial activity of Arctium lappa constituents against microorganisms commonly found in endodontic infections. Braz Dent J 2005;16:192-196.

\section{Abbreviations and Acronyms}

NPWT $=$ negative pressure wound therapy 